\title{
Adapted Dance Used in Subacute Rehabilitation Post-Stroke: Impacts Perceived by Patients, Relatives and Rehabilitation Therapists
}

Running title:

Dance and Stroke Rehabilitation: Perceived Impacts

Qualitative study

Lucie Beaudry ${ }^{1-2}$, Sylvie Fortin ${ }^{1}$ and Annie Rochette ${ }^{2-3}$

1. Department of Dance, Université du Québec à Montréal, Montreal, Canada

2. Centre for Interdisciplinary Research in Rehabilitation (CRIR) of Greater Montreal, Canada

3. School of Rehabilitation, Université de Montréal, Montreal, Canada

Corresponding author:

Lucie Beaudry (professor), Université du Québec à Montréal, Department of Dance, C.P. 8888, Succursale Centre-Ville, Montreal, Quebec, Canada, H3C 3P8. Tel.: 1-514-987-3000, ext. 5512. Email: beaudry.lucie@uqam.ca 


\section{Adapted Dance Used in Subacute Rehabilitation Post-Stroke: Impacts Perceived by Patients, Relatives and Rehabilitation Therapists}

Purpose: To examine the perceived impacts of an adapted-dance group intervention when added to intensive functional rehabilitation post-stroke. Method: In this exploratory qualitative case study, semi-structured interviews were analyzed using a deliberative inductive logic and referring to the International Classification of Functioning, Disability and Health. Participants were patients in rehabilitation post-stroke ( $\leq 25$ days $)(n=6)$, relatives $(n=4)$ and rehabilitation therapists $(n=12)$. Selection was on a voluntary basis. The intervention added to the patients' rehabilitation program consisted of 55-minute bi-weekly sessions for 10 weeks. Results: Three categories of perceived positive impacts emerged from the data: (1) mobility, (2) mental functions and personal factors (emotional functions, motivation and self-efficacy) and (3) interpersonal interactions and social life. A fourth category of perceived impacts involving exercise tolerance was both positive, in terms of general physical endurance, and negative, in terms of a feeling of increased fatigue.

Conclusion: Such an adapted-dance intervention holds promise in subacute rehabilitation post-stroke. Its main strength lies in its perceived positive impact on mental functions, personal factors, and interpersonal and social interactions.

Keywords: adapted dance; stroke rehabilitation; mobility; mental functions; self-efficacy; interpersonal interactions 


\section{Introduction}

Rehabilitation research recommends starting rehabilitation soon after a stroke to optimize patients' neuroplastic potential [1], as the largest gains can be anticipated in the first three months [2]. The combination of early and intensive rehabilitation can impact patients' level of autonomy by the time they leave the hospital [3], hence the importance of improving early intervention strategies in the acute and subacute phases. Currently, the typical amount of rehabilitation offered during these phases remains insufficient $[4,5]$.

In the quest for ways to intensify and optimize rehabilitation, dance offers a promising option as it may promote adherence due to its enjoyable nature and may aid with both physical and cognitive impairments by offering combined stimulation [6-9]. Studies on dance in relation to stroke have been conducted mainly in the chronic phase. A feasibility study on the impacts of dance on gait and balance in 10 patients showed no difference in MiniBESTest scores, but the patients themselves perceived positive impacts [10]. One case study demonstrated positive effects on balance, mobility, endurance and dual-task ability [11], while a multiple case study cited various physical, emotional and social improvements perceived by patients after three years of dance activities at the rate of one hour a week [12]. A virtual reality-based aerobic dance study involving 11 patients showed benefits for cardiac autonomic modulation [13] and upper limb performance [14]. Very few studies have been conducted in the subacute phase, most likely due to the challenges of conducting such an intervention in this context. Yet, pilot projects have demonstrated the feasibility of introducing these interventions during this phase $[15,16]$. One such study documented patients' positive perceptions of their balance and confidence, while cautioning against the risk of increased fatigue after more than 45 minutes of moderate-intensity jazz and merengue dancing [15]. 
The purpose of this qualitative study was to examine the perceived impacts of an adapteddance intervention when added to the intensive functional rehabilitation of patients in the subacute phase post-stroke, and to identify which impacts might be perceived as lasting at three months' post-intervention. The intervention took place within the first three months following the stroke on the premise that the patients', relatives' and rehabilitation therapists' perceptions would shed more light on the potential offered by dance in this specific context. The study thus sought to contribute to the development of an innovative type of intervention that may be relevant to stroke survivors [17].

\section{Method}

This qualitative study consisted of an exploratory case study [18]. The case was defined as the perceived impacts of an adapted-dance intervention for which the potential outcomes have yet to be examined. The study was based on semi-structured interviews conducted with stroke patients (who participated in both the study and the intervention), relatives (who participated in the study and periodically in the intervention), and rehabilitation therapists (who participated in the study or both the study and the intervention). The first round of interviews was designed to identify perceived impacts at the end of the intervention, while the second round served to identify the perceived lasting impacts three months later. Part of an interpretive research paradigm, this methodology allowed the perspectives of the main stakeholders concerned by our adapted-dance intervention to be studied via a subjectivist epistemology [19]. 


\section{Participants and recruitment}

Participants included stroke patients, relatives and rehabilitation therapists. Participating patients were adults who had had a recent stroke ( $\leq 25$ days) and were beginning their intensive functional rehabilitation in a rehabilitation hospital offering inpatient and outpatient neurological care. All were eligible for inclusion, irrespective of their neurological impairments. However, they had to have sufficient cognitive capacities to give their informed consent and to participate in the planned interviews (expressive aphasia cases with potential for progress during the project were not excluded). All the patients participating in the study participated in the adapted-dance intervention. Relatives were spouses or other adult family members who were in close contact with the patient and willing to participate in one or more adapted-dance sessions. Rehabilitation therapists included the participating patients' treating professionals (physiotherapists, occupational therapists and speech language pathologists), as well as the rehabilitation assistants participating in the adapted-dance sessions. All participants had to be able to communicate in either French or English.

A professional neurological care coordinator at the institution performed patient screening, while the researcher-dance educator performed participant recruitment. A maximum of six patients was sought to ensure the safety of the intervention. Once a patient was recruited, one relative was recruited for that patient whenever possible and invited to take part in the adapteddance sessions (limited to one, due to the capacity of the dance-session room). An average of two treating professionals per patient was then recruited in order to collect multiple viewpoints. Any given professional was invited to participate in the study in relation to one or more patients. A few rehabilitation assistants were also recruited during the study to fill in when a given assistant 
could not attend all the dance sessions. All participation in the project was voluntary. The study received prior ethics approval from both the university and the hospital institution.

\section{Description of the Intervention - Template for Intervention Description and Replication (TIDieR) Checklist}

The TIDieR is a 12-item checklist used to better report interventions [20]. In this article, we used this tool to briefly describe our adapted-dance intervention. It should be noted that, in preparation for the intervention, we first conducted a focus group with treating professionals, and we observed physiotherapy and occupational therapy treatments. We also offered the treating professionals introductory sessions on adapted dance to ensure that the intervention was perceived as safe and potentially complementary to their treatments.

The adapted-dance intervention consisted of 55-minute bi-weekly sessions for a maximum of 10 weeks (i.e., 20 sessions, depending on when the patient was recruited), and focused on the mid-range intensity (from moderate to hard) of the Borg Rating of Perceived Exertion Scale [21]. The intervention took place in a multifunctional room of a rehabilitation hospital providing neurological rehabilitation services, and was added to the participating patients' rehabilitation program. It began after four patients had been recruited, while the others (up to a maximum of 6 ) were added within $\leq 14$ days (for a maximum of 6 ). The intervention was initially based on dance and movement-based educational approaches (structured and improvised movements, expressive, rhythmic and synchronized movements in groups or pairs, sensory awareness and breathing). It was also based on rehabilitation practices and the therapists' movement recommendations that emerged from the focus group held in the preparation phase (self-assisted and sliding movements, anteriorization movements, movement symmetrization, weight transfer and pre-walking movements, movements triggering automatic motor reflexes, 
strategies for counteracting hyperreliance on compensatory movements, and integration of voice).

These movements were accompanied by music and organized into a welcoming routine involving warm-up exercises ( $\sim 16 \mathrm{~min}$.), a rhythmic segment ( $\sim 12 \mathrm{~min}$.), a standing segment when possible, but otherwise adapted to a sitting position ( $\sim 13 \mathrm{~min}$.), a segment involving the upper extremities ( $\sim 7 \mathrm{~min}$.), and a stretching/relaxation segment within a closing routine ( $\sim 7 \mathrm{~min}$.). Most of the intervention was performed on a chair in a circle formation. Technical aids were used as needed to facilitate participation. The researcher-dance educator planned the intervention, demonstrated and verbally guided the movements. A rehabilitation assistant danced within the group and provided physical assistance to patients as needed. To promote adherence to the intervention, hospital staff helped the hospitalized patients get to the dance room. A free taxi service was later offered to those who wanted to continue participating when they became outpatients after being discharged from in-patient services. As previously mentioned, one relative per patient was also invited to take part in the sessions. An extra session was added at the end of the project for a wind-up celebration.

\section{Data collection}

Personal and medical information was collected from each patient's medical records (see Table 1). All the interviews were conducted in person at the rehabilitation hospital by a research assistant who had not been in prior contact with the participants. A first round of interviews was conducted with each of the three categories of participants during either the last week of the patients' participation in the adapted-dance intervention or the following week. Interviews were conducted with the treating professionals at the time of the patients' in-patient discharge. The interview guide included general questions such as "Do you have the impression that the adapted dance might have contributed to your/the rehabilitation? What were the impacts it had, in your 
opinion? Any positive impacts?" and "Any negative impacts?" Interviews were also conducted with patients and relatives at a three-month post-intervention follow-up. This time, the interview guide contained one main question: "What impacts did you associate with the adapted-dance intervention [three months ago] and are still present today?" The interviews were all digitally recorded and transcribed, and the participants' names were anonymized. In one case of persistent expressive aphasia, the interviews took the form of "interview-questionnaires" involving closed questions (eliciting "yes/no" answers) and were filmed to obtain complementary data from the patient's non-verbal language.

\section{Analysis}

The semi-structured interviews were analyzed using a deliberative inductive logic [22] and referring to the International Classification of Functioning, Disability and Health (ICF) [23]. The ICF was used as a tool to guide the analysis process, while allowing perceived impacts not classified in the ICF to emerge. A printout of the interview transcripts was first analyzed to initially segment the data and identify units of meaning without referring to the ICF. These units of meaning were discussed by the research team until consensus was reached. All interviews were then coded and an analytical exercise was conducted using NVivo software to triangulate the data by unit of meaning. This allowed for differentiation among the perspectives of the three categories of participants and for frequency analysis. These units of meaning - which consisted of perceived impacts - were then linked to the ICF classification when applicable and the ICF terminology was retained, except for those not classified in the ICF. In these cases, we retained the participants' terms (or an overarching term that best encompassed the various terms used for a given unit of meaning). The outcome of that process was that most of the perceived impacts analyzed were found in the ICF, and we were thus able to present them under its components and 
domains when we categorized the perceived impacts (see the Results section). The other perceived impacts not classified in the ICF could still be included in one ICF component, in accordance with the generic definition of Personal Factors. That component was therefore also used in the perceived-impact categorization (explained in the Results section).

\section{Results}

All the individuals invited to participate in the study accepted the invitation, specifically, six patients, four relatives (for patients 2, 4, 5 and 6) and 12 rehabilitation therapists, for a total of 22 participants. Of the six patients who participated in both our study and intervention, two were unable to participate in the post-intervention follow-up interview, one due to unavailability and the other for health reasons. Mean patient age was $71.0 \pm 9.9$ years (range 59-86), and the group included an equal number of men and women. All of them have had an ischemic stroke within the previous four to 25 days. Table 1 highlights the heterogeneity of the cases in terms of ambulatory capacity, post-stroke sequelae and other conditions. Three patients completed all the adapted-dance sessions using a wheelchair, as did one other patient up until the $15^{\text {th }}$ session. One female patient was ambulatory and had mainly cognitive sequelae. Two female patients had a language disorder (severe aphasia in one case, Parkinson's disease in the other); it was harder for them to enunciate their thoughts during the interviews, which explains the fewer citations included from them in our results. An adherence rate of $82 \%$ was observed, and one patient attended the sessions irregularly due to fatigue and lack of interest (38\% - Patient 1$)$. Relatives included one wife, two daughters and one brother. Of the 12 rehabilitation therapists, eight participated in the study as treating professionals, and four participated in both the interviews and the adapted-dance sessions as rehabilitation assistants. The eight treating professionals consisted 
of three physiotherapists/PT, three occupational therapists/OT and two speech language

pathologists/SLP. Five of the eight participated for a single patient, while three participated for

two or more patients.

Table 1. Characteristics of patients $(n=6)$ and relationship of relatives $(n=4)$

\begin{tabular}{|c|c|c|c|c|c|c|c|c|c|}
\hline Patient & Age & Gender & $\begin{array}{l}\text { Hemi. } \\
\text { involved }\end{array}$ & $\begin{array}{l}\text { Days } \\
\text { since } \\
\text { stroke }\end{array}$ & $\begin{array}{l}\text { Days } \\
\text { since } \\
\text { starting } \\
\text { IFR }\end{array}$ & Ambulation & $\begin{array}{l}\text { Sequelae of the stroke } \\
\text { (+ other conditions) }\end{array}$ & $\begin{array}{l}\text { Dance } \\
\text { history }\end{array}$ & Relative \\
\hline Patient 1 & 86 & Male & Left & 25 & 10 & Wheelchair & $\begin{array}{l}\text { Mixed aphasia (expressive }+ \text { ) } \\
\text { Attention, memory } \\
\text { Dysphagia } \\
\text { Unilateral visual neglect } \\
\text { Hemiparesis, hemiplegia } \\
\text { Hypoesthesia } \\
\text { Fatigue }\end{array}$ & No & --- \\
\hline Patient 2 & 69 & Male & Left & 24 & 4 & $\begin{array}{l}\text { 4-legged cane } \\
+ \text { assistance } \\
\text { from one } \\
\text { person }\end{array}$ & $\begin{array}{l}\text { Attention, memory } \\
\text { Dysphagia } \\
\text { Hemiparesthesia, hemiparesis } \\
\text { Emotional lability } \\
\text { Other: pain in lower back }\end{array}$ & No & wife \\
\hline Patient 3 & 59 & Female & Left & 13 & 5 & Wheelchair & $\begin{array}{l}\text { Mixed aphasia (expressive } \\
+++ \text { ) } \\
\text { Dysphagia } \\
\text { Hemiparesthesia, hemiplegia } \\
\text { Emotions/Mood disorders } \\
\text { Other: pain wrist, obesity }\end{array}$ & No & --- \\
\hline Patient 4 & 76 & Female & Left & 22 & 2 & Ambulatory & $\begin{array}{l}\text { Attention, impulsivity, } \\
\text { planning, distracted, } \\
\text { perseverance, problem solving } \\
\text { Other: pain head, dizzy spells }\end{array}$ & Yes & daughter \\
\hline Patient 5 & 74 & Female & Left & 11 & 6 & Wheelchair & $\begin{array}{l}\text { Mixed aphasia (expressive }++ \text { ) } \\
\text { Hemiplegia } \\
\text { Other: Parkinson's, dystonia } \\
\text { arm }\end{array}$ & Yes & daughter \\
\hline Patient 6 & 62 & Male & Right & 12 & 3 & Wheelchair & $\begin{array}{l}\text { Attention/concentration, } \\
\text { memory } \\
\text { Dysarthria, dysphagia } \\
\text { Hemiparesis } \\
\text { Other: mild headache }\end{array}$ & Yes & brother \\
\hline
\end{tabular}

IFR $=$ Intensive functional rehabilitation 


\section{Perceived impacts of the adapted-dance intervention}

The participants perceived several impacts, with the exception of one patient who reported none (Patient 1). Analysis of the interviews with patients, relatives, and rehabilitation therapists revealed three main categories of perceived positive impacts. Using ICF terminology, these perceived impacts referred to (1) mobility, (2) mental functions and personal factors, and (3) interpersonal interactions and social life. A fourth category of perceived impacts involving exercise tolerance was both positive, in terms of general physical endurance, and negative, in terms of a feeling of increased fatigue. Before presenting these categories, it is important to recall that our intervention was added to the conventional therapies. Therefore, the perceived impacts cannot be attributed solely to our intervention, not to mention the fact that participants' perceptions may also have been biased by the spontaneous recovery that can occur in the first months after stroke. In the following sections, four tables summarize the perceived impacts, shown in bold. For each perceived-impact category, we present citations in a table and report the frequency of the perceived impacts in one column. Each category is followed by a paragraph presenting supporting citations to summarize the post-intervention follow-up interview with patients and relatives.

\section{Perceived-impact category \#1 - Mobility}

This category refers either to the Mobility domain defined in the ICF's Activities and Participation component, or to the neuromusculoskeletal and movement-related functions associated with the ICF's Body Functions component (see Table 2). All the terms used in this category correspond to those used in either of these two components of the ICF. The notion of balance (which falls under Sensory and Vestibular Functions in the ICF) has been included in this 
category since the participants associated it with the ability to stand and walk. This category

emerged more evidently among patients and relatives than among rehabilitation professionals, although the perception expressed by the latter was that dance was likely relevant to mobility.

The stroke patients and relatives perceived improvements related to changing and maintaining body position, such as being able to adopt or change a position, lie down, sit down, stand up, or change their centre of gravity, and in fine hand use, such as handling objects using their hand, fingers and thumb. This type of impact was perceived in patients 2 and 4, whose upper limb was less severely impaired. Mention was made of improvements in joint mobility, which refers to range and ease of movement of a joint as defined in the ICF, and of muscle power (strength) and muscle tone. The three categories of participants perceived improvements in terms of walking, that is, the ability to move a foot forward, step by step, to move around in different locations, such as going from one room to another, and to walk certain distances. They also reported perceived impacts in terms of balance, as well as control and coordination of voluntary movements, such as right/left motor coordination.

Table 2. Perceived-impact category \#1 - Mobility

\begin{tabular}{|c|c|c|}
\hline \multicolumn{2}{|c|}{ Activities and Participation } & \multirow{2}{*}{ Frequency } \\
\hline Changin & g and maintaining body position & \\
\hline PA5 & "[Adapted-dance] helped me stand without difficulty." & \\
\hline REL5 & $\begin{array}{l}\text { "It [had] also helped her to sit down on a chair, to move backwards. In her bed, she used to have difficulty } \\
{[\ldots] \text { lying down. Now, it's more fluid when she goes from sitting to lying." }}\end{array}$ & \\
\hline \multicolumn{2}{|r|}{ Fine hand use } & 4 \\
\hline PA2 & $\begin{array}{l}\text { "I can make little movements and shave myself with my right hand [and] it's thanks to the little gestures } \\
\text { that we made [in dance]." }\end{array}$ & \\
\hline REL2 & $\begin{array}{l}\text { "[He is] capable, with the fingers of his right hand }[\ldots] \text { to do }[\text { some }] \text { little, delicate things }[\ldots] \text {; he no } \\
\text { longer asks me, he does them himself." }\end{array}$ & \\
\hline \multicolumn{2}{|r|}{ Walking } & 6 \\
\hline PA2 & "I got better at lifting my feet, at lifting them higher, at walking more flexibly [smoother]." & \\
\hline REL2 & "He's a lot more solid and he walks more." & \\
\hline PT2 & $\begin{array}{l}\text { "Less [need] for a technical aid when walking. The patient [used to use] a four-legged cane; he became } \\
\text { more autonomous [getting around] with no technical aid inside the hospital. So, greater autonomy." }\end{array}$ & \\
\hline OT1 & $\begin{array}{l}\text { "I have the impression that it may have had an impact on mobility in general, }[\ldots] \text { when he was moving } \\
\text { around." }\end{array}$ & \\
\hline \multicolumn{3}{|c|}{ Balance } \\
\hline & "It [adapted dance] helped [me] regain a little more balance." & 5 \\
\hline
\end{tabular}


PA4 "While I was tap[ping] with my foot, I was clap[ping] with my hand [...]. I mean... I'm not explaining myself well [Are you talking about coordination?] Exactly, that's it [...]. It made my brain work. You [my foot], you go left, the other [my hand], you go right."

REL4 "It helped her a lot with right-left [movements]. [And] to be faster [in making them]."

Joint mobility

PA2 "[It] helped me raise my arm much higher."

REL5 "Her arm didn't used to lift up much, but now, it lifts up quite well, [and] her movement is smoother."

Muscle power (strength) - Muscle tone

PA2 "My entire right side has gotten quite a lot stronger."

PA5 "[Adapted dance] helped me remain standing [because it] gave me strength."

REL5 "When you lie down for a long time, or when you sit for a long time, it's like you have no more muscle tone, so to get the legs moving by tapping, and then moving the feet, [that helped my mother] to get back the muscle tone."

$\mathrm{PA}=$ Patient REL = Relative; $\mathrm{PT}=$ Physiotherapist OT $=$ Occupational therapist SLP $=$ Speech language pathologist; $\mathrm{AS}=$ Rehabilitation assistant; Frequency $=$ perceived-impact's frequency $/ \mathrm{n}=22$ participants

\section{Three-month post-intervention follow-up}

No regression was mentioned regarding the perceived positive impacts on mobility. However, the participants interviewed said that maintaining the gains had required staying active. This was the case with patients 3 and 6, who were still hospitalized and continuing their therapies. It was also the case with three other patients who had been discharged from the hospital for over three months. "It has [all the gains have] been maintained [...]. It's getting better all the time" (Patient 2); "In terms of movement fluidity, [some] changes in position [and] all that, yes [that's been maintained]" (Patient 5's relative). The daughter of Patient 4 said her mother had maintained the gains "because she still practices [used to practice the movements]. She does [was doing] them all the time, and if she doesn't [didn't] get them, she does [would do] them over and over again."

\section{Perceived-impact category \#2 - Mental Functions and Personal Factors}

In the ICF, the emotional and psychological dimensions of the person are classified under Body Functions, specifically, Mental Functions. By contrast, internal factors such as a feeling of wellbeing, confidence in one's abilities and confidence in one's balance, which can affect functioning and disability, fall under Personal Factors. Since these internal factors are not classified in the 
ICF, the related perceived impacts are presented using the terms used by the participants in the interviews.

Among the perceived positive impacts that can be grouped under Mental Functions and Personal Factors (see Table 3), there were perceived improvements associated with emotional functions, particularly in terms of morale and mood. Comments such as it "made people smile," "had a calming effect" and "boosted morale" came up frequently in the interviews with patients, relatives and rehabilitation therapists. The enjoyable nature of dance helped lighten an oftendifficult life situation. Dancing was perceived as contributing to the work of the treating professionals and the patients' rehabilitation process. Perceived positive impacts on motivation also emerged clearly from the data. For some, the adapted-dance intervention may even have served as a catalyst for greater involvement in rehabilitation. The data indicate that motivation was related to the development of greater confidence in their abilities, as both were often mentioned together in the comments collected. Regarding confidence, participants sometimes talked about improved confidence in their balance. They also mentioned a feeling of well-being that they experienced and perceived during and at the end of the adapted-dance sessions. The patients and relatives repeatedly said "it did [me] good," while the rehabilitation assistants remarked that the patients "looked like they felt good." 
Table 3. Perceived-impact category \#2 - Mental Functions and Personal Factors

\begin{tabular}{|c|c|c|}
\hline & Mental Functions & Frequency \\
\hline \multicolumn{2}{|c|}{ Emotional functions } & 15 \\
\hline PA2 & $\begin{array}{l}\text { "Personally, within [myself] it }[\ldots] \text { freed me up, as if it lifted a burden off my shoulders. Because } \\
\text { sometimes, you felt overwhelmed..." }\end{array}$ & \\
\hline REL5 & "I felt that for some people, it brought them relief, a sense of peace." & \\
\hline PT3 & $\begin{array}{l}\text { "Initially it was difficult with [this lady]. She was reacting very strongly to what had happened to her. } \\
\text { She would cry a lot }[\ldots . . .] \text {, there were lots of tears, [she had] a sadder face and tended to have more } \\
\text { outbursts. Now, when we're using dance, we see a bigger smile on her face, that she's more motivated, } \\
\text { that she's more cheerful. [I] think we can relate this to the adapted-dance project, more in terms of her } \\
\text { reactions, her emotivity, her motivation to do the therapies [...]. She's also in a better mood more often } \\
\text { [...], it's easier for everyone." }\end{array}$ & \\
\hline \multicolumn{2}{|r|}{ Motivation } & 15 \\
\hline PA2 & $\begin{array}{l}\text { "There, we were motivated to move with the music and the atmosphere in the group [...], it helped us a } \\
\text { lot." }\end{array}$ & \\
\hline REL5 & $\begin{array}{l}\text { "Of all the treatments she's done }[\ldots] \text {, this is what drove her. [Dancing] provided a motivation."; "People } \\
\text { were motivated to see themselves evolve in the movements." }\end{array}$ & \\
\hline REL5 & $\begin{array}{l}\text { "[As you learn movements and get better], that gives you some motivation, I think. I saw that in the eyes } \\
\text { of PA6, PA3 and all the other people who were there [not just my mother]. The same spark in their } \\
\text { eyes... of wanting to." }\end{array}$ & \\
\hline \multirow[t]{2}{*}{ PT6 } & $\begin{array}{l}\text { "Being able to resume a leisure activity that he used to do before, that was a trigger, I think. [To] see } \\
\text { that he could start dancing again, that made him happy and it gave him like a little boost for his } \\
\text { rehabilitation." }\end{array}$ & \\
\hline & Personal Factors & \\
\hline \multicolumn{2}{|c|}{ Feeling of well-being } & 11 \\
\hline PA4 & "It did [felt] good." & \\
\hline PA6 & $\begin{array}{l}\text { "You come out of there healthy. You're glad you spent time on something nice.... I like it because there's } \\
\text { something I feel in there... It makes me feel good." }\end{array}$ & \\
\hline REL5 & "I saw a sense of well-being [in my mother]", "she felt good doing it [adapted dance]." & \\
\hline PT5 & "I think it [adapted dance] allowed the patient to find a sense of well-being." & \\
\hline AS1 & "They [the patients] looked like they felt good." & \\
\hline \multicolumn{2}{|c|}{ Confidence in their abilities - Confidence in their balance } & 9 \\
\hline REL2 & $\begin{array}{l}\text { "They were learning... Learning that they [were] able to go further, slowly, but further. [My husband] } \\
\text { has more confidence when he walks or climbs [stairs], when he does things. [...] He has a lot more } \\
\text { confidence than he had before it [adapted dance] started." }\end{array}$ & \\
\hline REL5 & $\begin{array}{l}\text { "[Y]ou say to yourself that these are movements I'll never make again, I'll never be able to... And then, } \\
\text { [without even realizing it] you make them [...] Then the next time, well, you've [already] done it, so it } \\
\text { becomes, like I was able to do that, I'm able to go even further. You become more confident." }\end{array}$ & \\
\hline REL5 & $\begin{array}{l}\text { "At the beginning, she had problems with balance, with feeling confident about her balance [but now] } \\
\text { she has regain[ed] more of that confidence, which she wasn't [even] trying out [before]." }\end{array}$ & \\
\hline PT5 & $\begin{array}{l}\text { [The patient] came [here] absolutely terrified of falling [...]. Anything to do with movement, anything } \\
\text { that meant standing up was hard for her. I have the impression that the fact of doing it in adapted dance, } \\
\text { of dancing, of being there with other people who are also going through hard things, both in terms of } \\
\text { desensitizing her and psychologically, I think that it has had some impacts." }\end{array}$ & \\
\hline
\end{tabular}

\section{Three-month post-intervention follow-up}

The positive impacts perceived to have lasted concern primarily confidence in their abilities and motivation: “There were times when I used to say to myself, 'No, that'll never come back.' [T]oday, I say to myself, yes, it's possible. You've just gotta believe it. Gotta work on it. Gotta 
tell yourself that it's possible [...], yes-yes-yes... I believe it" (Patient 6). Relatives expressed the same idea: "He's got a lot more confidence than he used to have before doing [adapted dance]. He knows he can do [it]" (Patient 2's relative); she has "kept her motivation" (Patient 5's relative).

\section{Perceived-impact category \#3 - Interpersonal Interactions and Social Life}

As shown in Table 4, perceived impacts were related to interpersonal interactions and social life, two constituents of the Activity and Participation component of the ICF. Some patients had no inclination to interact socially or socialize before the study, but the adapteddance sessions were perceived as having contributed to foster this desire. Patients, relatives and rehabilitation therapists repeatedly mentioned that "it broke the isolation." In terms of social relationships within the group, comments made to each other about clothing, jewellery and hair suggested that the patients paid attention to their appearance when coming to dance.

The perceived social interactions generated by the study had ripple effects outside the adapteddance sessions, impacting the rehabilitation process as well as the desire to engage in a recreational type of activity [dance] after leaving the hospital. At the end of the intervention, four of the six patients expressed interest in continuing to dance. Their comments appeared closely related to the group effect and the social dimension of dance. Three of the four patients who were discharged from in-patient services during our study in fact continued dancing as outpatients after leaving the hospital. 
Table 4. Perceived-impact category \#3 - Interpersonal Interactions and Social Life

\begin{tabular}{|c|c|c|}
\hline \multicolumn{2}{|r|}{ Activity and Participation } & Frequency \\
\hline \multicolumn{2}{|c|}{ Interact socially or socialize - Social relationship } & 21 \\
\hline PA2 & $\begin{array}{l}\text { "The atmosphere in the group was very good. I can say that we made friends pretty quickly because we } \\
\text { were talking to each other [...]." }\end{array}$ & \\
\hline PA5 & "The fact of getting together twice a week, that had helped [me] to be more sociable." & \\
\hline PA6 & $\begin{array}{l}\text { "It was enough to be with people. [Through the] movements themselves... there was a form of } \\
\text { communication." }\end{array}$ & \\
\hline REL2 & $\begin{array}{l}\text { "[My husband] tended to withdraw, not to go up to people. [Dancing], that brought him out of his shell. } \\
\text { And a lot." }\end{array}$ & \\
\hline REL4 & $\begin{array}{l}\text { "[My mother] is very reserved. [She]'s not a woman who's going to go up and say hello. But there, she'd } \\
\text { go to people, she'd go up and talk to people, 'How are you? I see you moving, good for you.'; '[There } \\
\text { were comments like] 'Ah! Today you're walking! You did your hair.' }\end{array}$ & \\
\hline OT2 & $\begin{array}{l}\text { "[They] move around, greet each other, run into each other again, say hello, ask how things are going, } \\
\text { they encourage each other in the therapy room. So instead of finding themselves doing the therapy just } \\
\text { with the therapist, they support each other, they run into each other, they see each other outside the } \\
\text { therapy room. That's good. It means they're active longer during their day because they can socialize } \\
\text { with other people." }\end{array}$ & \\
\hline AS4 & "I think it had a major social impact." & \\
\hline \multicolumn{2}{|c|}{ Engagement in a recreational type of activity [dance] } & 15 \\
\hline PA2 & "If there were other sessions, I'd do it." & \\
\hline PA5 & "I'd like to continue, going to dance [...]." & \\
\hline PA6 & $\begin{array}{l}\text { "There are people I saw there who never missed a day. [...] So that means that this dance held real } \\
\text { interest for these people."; [To his visiting brother] "I said, 'Please excuse me, I have something to do } \\
\text { [adapted dance], I haven't finished my activities. You arrived before I finished. '. It's an activity I love. } \\
\text { I left [him] so I could be there." }\end{array}$ & \\
\hline REL5 & $\begin{array}{l}\text { "Whenever there was dance, there was no question of her missing it"; "She'd continue [dancing], she } \\
\text { just loved that." }\end{array}$ & \\
\hline REL6 & "I think that if we can recreate the context (the adapted aspect), [he]'ll continue to dance." & \\
\hline SLP3 & $\begin{array}{l}\text { "She always told me that at } 3 \text { o'clock she had to leave, that she shouldn't be late because she had her } \\
\text { dance class." }\end{array}$ & \\
\hline AS1 & $\begin{array}{l}\text { "There were some who had had a big stroke yet they persevered, }[\ldots] \text { against all odds, [their] presence, } \\
\text { enthusiasm, I found it extraordinary." }\end{array}$ & \\
\hline AS3 & "The fact that they were there... it's because they wanted to be there." & \\
\hline
\end{tabular}

$\mathrm{PA}=$ Patient REL = Relative; $\mathrm{OT}=$ Occupational therapist; SLP $=$ Speech language pathologist;

$\mathrm{AS}=$ Rehabilitation assistant; Frequency $=$ perceived-impact's frequency $/ \mathrm{n}=22$ participants

Three-month post-intervention follow-up

The interpersonal interactions were perceived as leaving positive imprints extending beyond the adapted-dance group: “[...] I was a really, really shy guy before [but] since then, I chat a lot more with people than I used to" (Patient 2). One relative said she now encourages her mother's interactions, even if just by phone: "In the dance group, she was able to talk with the people around her. Now, even on the phone, I let her [talk, rather than talking for her]" (Patient 5's relative). One patient who was still hospitalized at the end of our intervention (Patient 6) joined another dance group offered in the rehabilitation hospital (for people who were more 
mobile/autonomous), confirming his brother's comments at the end of the intervention to the effect that he would continue dancing if he were offered the appropriate context.

\section{Perceived-impact category \#4 - Exercise Tolerance}

Fatiguability and general physical endurance fall under Exercise Tolerance functions which, according to the ICF, relate to the cardiovascular capacity needed to tolerate physical exertion. In this category, increased fatigue was the only negative perceived impact reported by three of the study participants (see Table 5). One patient said she sometimes felt more tired on days when she had done adapted dance. One relative had the impression that her mother might have felt a 'good fatigue' along with a feeling of pride and satisfaction after the dance sessions. One rehabilitation professional expressed concerns about the addition of our intervention for a patient who already had a problem with fatigue, mentioning on the other hand that adapted dance may have had a positive impact on his endurance. In this regard, some participants reported an improvement in overall endurance when interviewed post-intervention, although these perceptions did not emerge in the three-month post-intervention follow-up interview.

Table 5. Perceived-impact category \#4 - Exercise Tolerance

\begin{tabular}{|c|c|c|}
\hline & Exercise Tolerance Functions & Frequency \\
\hline \multicolumn{2}{|c|}{ Fatigue - Fatiguability } & \multirow[t]{4}{*}{3} \\
\hline PA4 & $\begin{array}{l}\text { "In the evening, I felt a little tired }[\ldots] \text {, because I could tell that I had done something. Not too much, } \\
\text { though, but I could see that it was a little different from other days [when I hadn't done dance]." }\end{array}$ & \\
\hline REL5 & $\begin{array}{l}\text { "It was a fatigue, but it was a good fatigue. [...] She was pleased with herself, she had done her dance } \\
\text { class." }\end{array}$ & \\
\hline PT1 & $\begin{array}{l}\text { "He sometimes told me that he hadn't gone [dancing] because he was too tired to go. [...] It [fatigue] } \\
\text { was kind of part of his profile, so it [adapted dance] may have had impacts since it was one more thing } \\
\text { in his day, it seemed to tire him out [when participating]." }\end{array}$ & \\
\hline \multicolumn{2}{|r|}{ General physical endurance } & 7 \\
\hline PA2 & $\begin{array}{l}\text { "[At first] I didn't stay up very long. I had to sit much faster. But as the dance progressed, I was able to } \\
\text { stand much longer, without shaking [in the legs]." }\end{array}$ & \\
\hline REL2 & "It's true that he gets tired more [when he gets active], that's normal. But he walks more, and for longer." & \\
\hline PT1 & "[I]n terms of his endurance, possibly [dance] has [had] a positive impact." & \\
\hline PT2 & "[I noticed an] increase in general endurance." & \\
\hline AS4 & "In terms of tolerance [effort], I'm sure it had an impact." & \\
\hline
\end{tabular}




\section{Discussion}

By carrying out our intervention within three months of the stroke, we sought to identify the potential that adapted dance may offer in the subacute phase of post-stroke rehabilitation. Our study does not allow us to attribute the participants' perceptions to adapted dance. Nevertheless, the four essential categories of perceived impacts appear to offer intervention targets worth considering in this context, as discussed below.

\section{Main strengths of adapted dance}

Since the probability of optimal recovery is low without the patient's participation in his or her rehabilitation, the notions of engagement, motivation, confidence, autonomy and social relations are of great importance, as pointed out in the literature [24]. In our study, several perceived positive impacts of adapted dance are congruent with this literature. In the following paragraphs, we address more specifically the related issues of mood and feeling of well-being, self-efficacy and motivation, and social interactions.

\section{Mood and feeling of well-being}

The patients' feeling of well-being and the good mood they experienced during the adapteddance sessions were among the strongest perceived positive impacts of the intervention, and contributed to their participation. According to some of the rehabilitation therapists involved, this may also have influenced the patients' participation in their overall rehabilitation. Feeling of well-being refers to happiness and the perception of confidence and self-esteem [25], while the term mood refers mainly to depression and anxiety disorders [26]. The perceived positive impacts of the intervention on "morale" and mood are of interest as the prevalence rates of depression and anxiety among stroke survivors are $24 \%$ and $29 \%$ respectively. These mood disorders can have a 
significant, adverse impact on post-stroke recovery [26]. This impact is partly attributable to the correlation existing between depression and the executive functions that are predictive of participation in rehabilitation [27]. While studies on physical exercise and mood disorders are not unanimous in their findings, some assert that exercise can reduce depression and anxiety [28]. From this perspective, adapted dance, which implicitly involves some sort of physical exercise, may be a worthwhile intervention to consider, particularly as its relational and social dimensions generate greater adherence than do other conventional physical activities [29, 30].

\section{Self-efficacy and motivation}

In our study, the perceived positive impacts on confidence in one's abilities referred to the patients' increased confidence in their ability to make a dance movement or perform a task outside the dance sessions. This echoes Bandura's feeling of personal efficacy (or self-efficacy) [31], which is the very foundation for motivation and action. Patients have few reasons to act or persevere in the face of obstacles if they themselves do not believe they can obtain the outcomes they wish to achieve through their actions [32]. The feeling of personal efficacy is regarded as an important predictor of disability following stroke [33] and can influence self-regulatory processes on cognitive, affective and behavioural levels. It is therefore relevant to examine the potential impacts of adapted dance on this psychological construct, particularly as the perceived positive impacts reported in our study were still perceived as lasting at the three-month post-intervention follow-up.

\section{Social interaction}

Along with its perceived impacts on mental functions and personal factors, in our study adapted dance was perceived as having impacted patients' social interaction. The group modality 
generated a variety of interactions for the patients. Our results attest to a camaraderie that fostered participation in the sessions. While it has been demonstrated that camaraderie can be experienced among patients in a post-stroke care unit providing individual therapies [34], the group intervention in adapted dance appears to go even further by opening the doorway to social participation through dance. Indeed, three of the four participating patients who left the hospital before the end of the adapted-dance intervention continued dancing until the end of the 10-week intervention (an engagement also facilitated by the availability of a taxi car service). Furthermore, four patients in the group expressed an interest in pursuing a dance activity post-rehabilitation (one in fact had the opportunity to do so and grabbed it). Given that interventions involving physical exercise can be effective in improving social participation [35], the bridge that adapted dance potentially builds between rehabilitation and social reintegration presents an avenue that warrants exploration. This is particularly so, as it would capitalize on the desire to socialize that was expressed by the patients and relatives at the three-month post-intervention follow-up interviews, while also addressing the need they cited to remain active in order to maintain their mobility gains (whether or not attributable to adapted dance). Such an intervention could be offered as part of a care continuum [5].

\section{Mobility as a logical target?}

The results of our study show that mobility may be a target for an adapted-dance intervention, but probably not the one to prioritize since it did not appear to be the most compelling perceivedimpact category. In the interviews, most of the participants perceived dance as a complementary means of tackling movement challenges in post-stroke rehabilitation. For them, it seemed "logical" to associate dance with mobility. This presumed complementarity was often mentioned in the interviews, but was less expressed as such when participants - especially the rehabilitation 
therapists - were asked to report perceived impacts. Based on our intervention experience, mobility constitutes a complex target for such an inclusive group intervention, as activity limitations can be very different from one patient to another. However, our results suggest that an intervention carried out mainly on a chair may still be relevant for targeting mobility, irrespective of the patient's ambulatory level.

\section{Exercise tolerance as a target ... with caution}

The results indicate that the intervention may have potential in terms of physical endurance without major fatigue-related perceived impacts. Even so, exercise tolerance represents a target that calls for adjustment and caution, especially since fatigue was not systematically documented after our adapted-dance sessions. Exercise can offer a strategy in itself for managing fatigue poststroke, but knowledge is still lacking about the interventions that should be given priority and about the effects of physical exercise on problems of fatigue and depression [36]. Given that onethird of brain-injured patients suffer from debilitating fatigue [37], the strong adherence to the adapted-dance intervention in our study and the few minor negative perceived impacts reported in terms of fatigue are noteworthy, particularly as the scheduling of the sessions (late afternoon, after the other therapies) may have contributed to increased fatigue. In one feasibility study on dance conducted in the subacute phase of stroke [15], patients reported slight to moderate fatigue after 45 minutes of moderate-intensity dance exercises, and significant fatigue beyond 45 minutes. The intervention's content and pedagogy may partly explain the differences in terms of perceived fatigue.

\section{Strengths and limitations of the study}

The selection of stroke patients with various neurological impairments reflected the heterogeneity 
of cases admitted to in-patient rehabilitation. Inclusion of the three main stakeholders concerned by post-stroke rehabilitation (patients, relatives and rehabilitation therapists) made it possible to differentiate between the impacts perceived by the three of them from more isolated ones.

Triangulation of the perceptions reported by the three categories of participants and use of the standardized language of the ICF, insofar as the data allowed, limited interpretation biases. The interviews were conducted by an assistant unknown to the participants in order to limit social desirability bias. That said, the participants may have been reticent to talk about their perceptions with a stranger [38]. The findings of this study cannot be generalized as it was a qualitative study with a very limited number of participants. The spontaneous recovery that can occur in the first few months following stroke, as well as the combination of adapted dance with conventional rehabilitation therapies, therefore represent possible limitations of our study. The participation of the researcher dance-educator in the analysis process is another limitation to be taken into consideration. However, our results offer relevant information that could provide guidance for the future development and evaluation of this type of intervention. While data saturation was favoured by the multiple perspectives and by the two interviews at different points in time (postintervention and follow-up), other types of perceived impacts could also emerge from another type of dance intervention or from another group of participants. Lastly, the participants' answers at the three-month post-intervention follow-up may have been subject to a recall bias [39] and to an attrition bias that was beyond our control.

\section{Conclusion}

Adapted dance is an innovative group intervention that holds promise in the context of subacute rehabilitation post-stroke. While it may seem "logical" that dance could potentially contribute to mobility, its perceived impact on mental functions and personal factors, as well as on 
interpersonal and social interactions, may well represent the main strength of this type of intervention in this particular context. The reported feelings of well-being and self-efficacy, as well as the improvement in mood and socialization, appear to have fostered participation in the intervention despite the presence of a feeling of fatigue for some participants. Adapted dance is an intervention modality worthy of consideration in intensive functional rehabilitation of stroke since the perceived impacts reported were essentially positive.

\section{Acknowledgements}

This study received financial support from the Université du Québec à Montréal for the purchase of audiovisual equipment and funding from the Institut Santé et Société for the English translation of this article. We greatly appreciate the time and thought that the participants put into the study, and the cooperation of the host institution.

\section{Declaration of interest statement}

The authors have no conflicts of interest to declare.

\section{References}

1. Oujamaa L, Marquer A, Francony G, et al. Intérêt d'une rééducation précoce pour les patients neurologiques [Merits of early re-education for neurological patients]. Ann Fr Anesth. 2012;31(10):253-263. French. doi:10.1016/j.annfar.2012.08.005

2. Deroide N, Nih LR, Tran Dinh RY, et al. Plasticité cérébrale : de la théorie à la pratique dans le traitement de l'accident vasculaire cérébral [Brain plasticity: from theory to practice in the treatment of stroke]. Rev Med Interne. 2010;31(7):486-492. French. doi:10.1016/j.revmed.2009.08.014

3. $\mathrm{Hu}$ MH, Hsu SS, Yip PK, et al. Early and intensive rehabilitation predicts good functional outcomes in patients admitted to the stroke intensive care unit. Disabil Rehabil. 2010;32(15):1251-1259. doi:10.3109/09638280903464448

4. Kwakkel G. Impact de l'intensité de la rééducation après AVC : problématique de la réflexion [Impact of the intensity of re-education after stroke: problematic issues emerging from reflection]. Ann Phys Rehabil Med. 2012;55(1):E2. French. doi:10.1016/j.rehab.2012.07.006

5. Richards, C. L. and Comité d'experts sur l'offre de services de réadaptation post-AVC. Trajectoires de services de réadaptation post-AVC. Un continuum centré sur la personne. [Post-stroke rehabilitation service trajectories. A person-centred continuum]. Ministère de 
la Santé et des Services sociaux, Québec Government, ed.: Les Publications du Québec; 2013. p. 104. French.

6. Dhami P, Moreno S, DeSouza JFX. New framework for rehabilitation - fusion of cognitive and physical rehabilitation: the hope for dancing. Front Psych. 2015;5:1-15. doi:10.3389/fpsyg.2015.00478

7. Fissler P, Küster O, Schlee W, et al. Novelty interventions to enhance broad cognitive abilities and prevent dementia: synergistic approaches for the facilitation of positive plastic change. Prog Brain Res. 2012;207:403-434. doi:10.1016/B978-0-444-633279.00017-5

8. Kraft E. Cognitive function, physical activity, and aging: possible biological links and implications for multimodal interventions. Aging Neuropsychol Cogn. 2012;19(1-2):248263. doi:10.1080/13825585.2011.645010

9. Olsson C-J. Dancing combines the essence for successful aging. Front Neurosci. 2012;6(155):1-2. doi:10.3389/fnins.2012.00155

10. Patterson KK, Wong JS, Nguyen, T-U, Brooks D. A dance program to improve gait and balance in individuals with chronic stroke: a feasibility study. Top Stroke Rehabil. 2016. doi: 10.1080/10749357.2018.1469714.

11. Hackney ME, Hall CD, Echt KV, et al. Application of adapted tango as therapeutic intervention for patients with chronic stroke. J Geriatr Phys Ther. 2012;35(4):206-217. doi:10.1519/JPT.0b013e31823ae6ea

12. Wolff S, Delabary M, Haas A. Can dance contribute to physical, emotional and social aspects of the stroke patient? Int J Ther Rehabil Res. 2017;6(1):70-74. doi:10.5455/ijtrr.000000223

13. Sampaio LMM, Subramaniam S, Arena R, et al. Does virtual reality-based Kinect dance training paradigm improve autonomic nervous system modulation in individuals with chronic stroke? J Vasc Interv Neurol. 2016;9(2):21-29.

14. Subramaniam S, Bhatt T. Virtual reality-based dance gaming improves performance of an instrumented functional arm reach task in community-dwelling chronic stroke survivors. J Hand Ther. 2016;29(2):e8-e8. doi:10.1016/j.jht.2016.02.019

15. Demers M, McKinley P, Tchounwou PB. Feasibility of delivering a dance intervention for subacute stroke in a rehabilitation hospital setting. Int J Environ Res Public Health. 2015;12(3):3120-3132. doi:10.3390/ijerph120303120.

16. Govare A, Gagnon M-J, Odier C, editors. Danse thérapie en réadaptation d'AVC: projet pilote [Dance therapy in stroke rehabilitation: pilot project]. Canadian Stroke Congress; 2014. Dallas, Texas: American Stroke Association. French.

17. Salter K, Hellings C, Foley N, et al. The experience of living with stroke: a qualitative metasynthesis. J Rehabil Med. 2008;40(8):595-602. doi:10.2340/16501977-0238

18. Yin RK. Case study research: design and methods ( $3^{\text {rd }}$ ed.). Thousand Oaks (CA): Sage; 2003.

19. Nayar S, Stanley M. Qualitative research methodologies for occupational science and therapy. New York (NY): Routledge; 2015.

20. Hoffmann TC, Glasziou PP, Boutron I, et al. Better reporting of interventions: template for intervention description and replication (TIDieR) checklist and guide. Br Med J. 2014;348:g1687. doi:10.1136/bmj.g1687

21. Borg GAV. Psychophysical bases of perceived exertion. Med Sci Sports Exerc. 1982;4(5):377-381. PubMed Central; PMCID: PMC7154893. 
22. Savoie-Zajc L. La recherche qualitative/interprétative en éducation [Qualitative/interpretive research in education]. In: Karsenti T, Savoie-Zajc L, editors. La recherche en éducation : étapes et approches [Research in education: steps and approaches]. 3rd ed. Sherbrooke (QC): Éditions du CRP; 2011. p. 123-150. French.

23. World Health Organization (WHO). International Classification of Functioning, Disability and Health: ICF. Geneva: World Health Organization; 2001.

24. Winstein C. The ATTEND trial: an alternative explanation with implications for future recovery and rehabilitation clinical trials. Int J Stroke. 2018;13(2):112-116. doi: $10.1177 / 1747493017743061$

25. Gillen G. Stroke rehabilitation: a function-based approach. 4th ed. St. Louis (MO): Mosby Elsevier; 2015.

26. Salter K, Mehta S, Cotoi A, et al. Post-stroke depression and mood disorders. In: Teasell R, Foley N, Hussein N, et al., editors. Evidence-based review of stroke rehabilitation Ontario, Canada: Canadian Partnership for Stroke Recovery (CPSR); 2016. p. 1-112.

27. Skidmore ER, Whyte EM, Holm MB, et al. Cognitive and affective predictors of rehabilitation participation after stroke. Arch Phys Med Rehabil. 2010;91(2):203-207. doi:10.1016/j.apmr.2009.10.026

28. American Stroke Association: Physical activity [Internet]. Centennial (CO): National Stroke Association; [updated 2015 Mar 9; cited 2018, Jan 18]. Available from: http://www.strokeassociation.org/STROKEORG/LifeAfterStroke/HealthyLivingAfterStro ke/PhysicalActivity/Physical-Activity_UCM_310896_Article.jsp - .Wk7P_ksiEUE

29. Foster ER, Golden L, Duncan RP, et al. A community-based Argentine Tango dance program is associated with increased activity participation among individuals with Parkinson's disease. Arch Phys Med Rehabil. 2013;94(2):240-249. doi:10.1016/j.apmr.2012.07.028

30. Kattenstroth J-C, Kalisch T, Holt S, et al. Six months of dance intervention enhances postural, sensorimotor, and cognitive performance in elderly without affecting cardiorespiratory functions. Front Aging Neurosci. 2013;5(5):1-16. doi:10.3389/fnagi.2013.00005

31. Bandura A. Self-efficacy: toward a unifying theory of behavioral change. Psychol Rev. 1977;84(2):191-215. doi:10.1037/0033-295X.84.2.191.

32. Carré P. Bandura : une psychologie pour le XXième siècle? [Bandura: a psychology for the $20^{\text {th }}$ century?]. Savoirs. 2004;5:9-50. French. doi:10.3917/savo.hs01.0009

33. LeBrasseur N, Sayers S, Ouellette M, et al. Muscle impairments and behavioural factors mediate functional limitations and disability following stroke. Phys Ther J.

2006;86(10):1342-1350. doi:10.2522/ptj.20050162

34. Lewinter M, Mikkelsen S. Patients' experience of rehabilitation after stroke. Disabil Rehabil. 1995;17(1):3-9.

35. Obembe AO, Eng JJ. Rehabilitation interventions for improving social participation after stroke : a systematic review and meta-analysis. Neurorehab Neural Re. 2016;30(4):384392. doi: $10.1177 / 1545968315597072$

36. Mead GE, Bernhardt J. Physical fitness training after stroke, time to implement what we know: more research is needed. Int J Stroke. 2011;6(6):506-508. doi:10.1111/j.17474949.2011.00679.x

37. MacIntosh BJ, Edwards JD, Kang M, et al. Fatigue a major barrier to physical, cognitive recovery after stroke, new study finds. Better diagnosis, more research neede to 
counteract debilitating condition. Front Aging Neurosci. 2017;9(343):1-7. doi:10.3389/fnagi.2017.00343

38. Reed M, Harrington R, Duggan A, et al. Meeting stroke survivors' perceived needs: a qualitative study of a community-based exercise and education scheme. Clin Rehabil. 2010;24(1):16-25. doi:10.1177/0269215509347433

39. Ford R, Bach SA, Fottler MD. Methods of measuring patient satisfaction in health care organizations. Health Care Manage Rev. 1997;22(2):74-89. 